\title{
Anhidrosis in the Horse (Non-Sweaters)—What Do We Know?'
}

\author{
Laura Patterson-Rosa, Martha F. Mallicote, Robert J. MacKay, and Samantha A. Brooks²
}

Anhidrosis refers to a temporary or complete loss of the ability to sweat (Breuhaus 2009). In horses, it is characterized by the reduced or lack of sweat response to increased body temperature. This is a poorly understood condition with a varying prevalence in the horse population. In Florida, one study found that $6 \%-25 \%$ of Thoroughbreds were diagnosed with anhidrosis at least once in their careers (Johnson et al. 2010). For non-racing horses, the incidence of anhidrosis varies between $2 \%$ and $11 \%$ of the horse population (Johnson et al. 2010). Although the condition is a particular concern in warm climates, horses in any environment can experience anhidrotic bouts during travel or a summer heatwave (MacKay et al. 2015). Owners may notice a partial or complete loss of sweat response, rapid breathing (tachypnea), elevated body temperature (hyperthermia), reduced appetite (anorexia), decreased water intake, hair loss (alopecia), dull hair coat, and depression. Severe cases result in collapse due to overheating, leading to convulsions, and without timely intervention, death. Anhidrotic horses suffer considerably during work and warm seasons, do not perform well athletically, and have a reduced quality of life (Jenkinson et al. 2006). These horses need intensive medical management and restricted physical activity in warm weather. They often must retire early from breeding or competition.
Healthy horses have a remarkably effective cooling system. Their sweat glands, which are distributed over most of the body surface, have the ability to move large volumes of water. In order to disperse excess body heat, the horse relies mostly on sweat evaporation. Still, the equine heat regulatory system can be overwhelmed, resulting in critical overheating. Environmental temperatures exceeding $77^{\circ} \mathrm{F}$ $\left(25^{\circ} \mathrm{C}\right)$ combined with $70 \%-90 \%$ relative humidity will begin to compromise heat loss through sweating, leading to an increase in body temperature. Without the sweat response, traveling a distance of roughly 2 miles at the gallop is estimated to increase the core temperature of a horse by $11^{\circ} \mathrm{F}$.

Overtraining and/or electrolyte imbalance can lead to exhaustion of cooling mechanisms and a temporary reduction in the ability to sweat. Drugs such as antihistamines and macrolide antibiotics can also lead to temporary anhidrosis, but this condition usually resolves in a matter of days or weeks once the drug is withheld (Stieler et al. 2015). In contrast, chronic idiopathic anhidrosis (CIA) occurs for more than one consecutive summer season and does not resolve despite changes in housing, diet, and exercise schedule (Johnson et al. 2010). An intradermal sweat test (with terbutaline) known as QITST can be used by veterinarians for quantification of the sweating capacity of horses. It can also aid in diagnosis of CIA (MacKay 2008). However, the factors that distinguish acute but reversible anhidrosis from

1. This document is AN362, one of a series of the Department of Animal Sciences, UF/IFAS Extension. Original publication date October 2020. Visit the EDIS website at https://edis.ifas.ufl.edu for the currently supported version of this publication.

2. Laura Patterson-Rosa, postdoctoral researcher, Department of Animal Sciences; Martha F. Mallicote, clinical associate professor, Department of Large Animal Clinical Sciences, College of Veterinary Medicine; Robert J. MacKay, professor, Department of Large Animal Clinical Sciences, College of Veterinary Medicine; and Samantha A. Brooks, associate professor, Department of Animal Sciences; UF/IFAS Extension, Gainesville, FL 32611.

The Institute of Food and Agricultural Sciences (IFAS) is an Equal Opportunity Institution authorized to provide research, educational information and other services

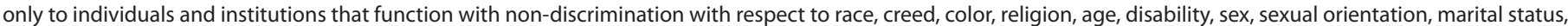

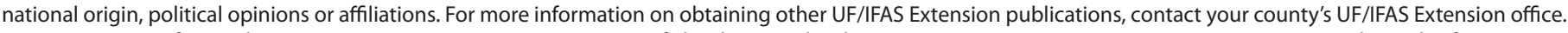
U.S. Department of Agriculture, UF/IFAS Extension Service, University of Florida, IFAS, Florida A \& M University Cooperative Extension Program, and Boards of County Commissioners Cooperating. Nick T. Place, dean for UF/IFAS Extension. 
a permanent loss of sweating ability are still unknown, and the underlying cause of chronic idiopathic anhidrosis remains unclear (Hubert and Beadle 2002).

Although horses competing in hot, tropical climates are at higher risk of these conditions, both chronic and acute anhidrosis are frequently recognized in many non-tropical regions, especially temperate climates with a sudden onset of hot and humid summers. Even if removed from the hot and humid climate, many anhidrotic horses never regain the ability to sweat normally. With a global rise in temperatures, this condition is likely to become more widespread in the future.

Numerous "treatments" are advertised for this condition. Most are based on speculation, anecdotal reports, and at best, uncontrolled and unreplicated studies conducted in a small set of horses (MacKay et al. 2015). Some attempted therapies include dietary supplements, electrolytes, methyldopa, clenbuterol, and thyroid supplementation. Alternative therapies such as acupuncture and herbal supplements are also popular, but were shown to be ineffective long-term in at least one report (Mallicote et al. 2013). To date, no treatment for anhidrosis has passed even the minimal standard for evidence-based medicine.

Environmental factors such as overtraining, failure to acclimate after travel to a hotter climate, electrolyte imbalance, and dehydration can trigger an acute anhidrotic episode (MacKay et al. 2015). However, CIA defies these trigger factors. A UF/IFAS study revealed that, at the individual level, the risk for anhidrosis varies significantly by breed, with Thoroughbreds and Warmbloods at higher risk. Johnson, MacKay, and Hernandez (2010) also observed that the odds of manifesting anhidrosis are 21.7 times higher in horses with a family history of the condition. These findings strongly support the theory that there is a hereditary/ genetic component contributing to anhidrosis in horses.

The heritable component of CIA disease suggests that we might limit the disease through genetic selection. Further research will inform efforts to develop preventive strategies, targeted treatments, and tools for early diagnosis/detection. It will also immediately permit selective breeding to eliminate hereditary risk factors. Novel treatments could help to alleviate symptoms in currently affected horses and improve the animals' quality of life. An understanding of the cause is key to the development of an effective treatment.

\section{Signs of Anhidrosis}

- Partial or complete loss of sweating

- Hyperthermia (overheating)

- Fast breathing with flared nostrils

- Reduced appetite

- Decreased water intake

- Hair loss, usually on chest, croup, and face

- Dull hair coat

- Depression

\section{Management Tips for the Chronically Anhidrotic Horse}

1. Work horses during the cooler parts of the day such as evening or early morning.

2. Observe the horse closely for signs of overheating such as rapid respiratory rate and high body temperature.

3. When introducing a new horse to a hot and humid climate, allow the horse to adjust with turnout time and light work.

4. Start your horses' spring/summer workout regime earlier, so that they are more fit for the hottest parts of the season.

5. Always make sure shade is available. Misters and fans can be used for added cooling.

6. Hosing off your horse during the hottest parts of the day will help keep its internal body temperature down.

\section{References}

Bovell, D. L., S. L. Lindsay, A. D. Corbett, and C. Steel. 2006. "Immunolocalization of Aquaporin-5 Expression in Sweat Gland Cells from Normal and Anhidrotic Horses." Veterinary Dermatology 17:17-23. https:/doi. org/10.1111/j.1365-3164.2005.00498.x

Breuhaus, B. A. 2009. "Thyroid Function in Anhidrotic Horses." Journal of Veterinary Internal Medicine 23: 168173. https://doi.org/10.1111/j.1939-1676.2008.0217.x 
Corbin, L. J., S. C. Blott, J. E. Swinburne, C. Sibbons, L. Y. Fox-Clipsham, M. Helwegen, T. D. H. Parkin, J. R. Newton, L. R. Bramlage, and C. W. Mcllwraith. 2012. "A GenomeWide Association Study of Osteochondritis Dissecans in the Thoroughbred." Mammalian Genome 23: 294-303. https://doi.org/10.1007/s00335-011-9363-1

Hubert, J. D., and R. E. Beadle. 2002. "Equine Anhidrosis." Veterinary Clinics of North America-Equine Practice 18: 355-369. https://doi.org/10.1016/S0749-0739(02)00016-0

Jenkinson, D. M., H. Y. Elder, and D. L. Bovell. 2006. "Equine Sweating and Anhidrosis-Part 1-Equine Sweating." Veterinary Dermatology 17: 361-392. https://doi. org/10.1111/j.1365-3164.2006.00545.x

Johnson, E. B., R. J. MacKay, and J. A. Hernandez. 2010. "An Epidemiologic Study of Anhidrosis in Horses in Florida." Journal of the American Veterinary Medical Association 236: 1091-1097. https://doi.org/10.2460/javma.236.10.1091

MacKay, R. J. 2008. "Quantitative Intradermal Terbutaline Sweat Test in Horses." Equine Veterinary Journal 40:

518-520. https://doi.org/10.2746/042516408X322409

MacKay, R. J., M. Mallicote, J. A. Hernandez, W. F. Craft, and J. A. Conway. 2015. "A Review of Anhidrosis in Horses." Equine Veterinary Education 27: 192-199. https:// doi.org/10.1111/eve.12220

Makvandi-Nejad, S., G. E. Hoffman, J. J. Allen, E. Chu, E. $\mathrm{Gu}$, A. M. Chandler, A. I. Loredo, R. R. Bellone, J. G. Mezey, S. A. Brooks, and N. B. Sutter. 2012. "Four Loci Explain 83\% of Size Variation in the Horse." PLOS ONE 7: e39929. https://doi.org/10.1371/journal.pone.0039929

Mallicote, M. F., C. I. Medina, H. Xie, J. Zilberschtein, S. Atria, M. Manzie, J. Hernandez, and R. J. MacKay. 2013. Acupuncture and Herbal Medicine Used for Treatment of Anhidrosis. Hoboken, NJ: Wiley-Blackwell.

Signer-Hasler, H., C. Flury, B. Haase, D. Burger, H. Simianer, T. Leeb, and S. Rieder. 2012. "A Genome-Wide Association Study Reveals Loci Influencing Height and Other Conformation Traits in Horses." PLOS ONE 7: e37282. https://doi.org/10.1371/journal.pone.0037282

Stieler, A. L., L. C. Sanchez, M. F. Mallicote, B. B. Martabano, J. A. Burrow, and R. J. MacKay. 2015. "MacrolideInduced Hyperthermia in Foals: Role of Impaired Sweat Responses." Equine Veterinary Journal. 48(5): 590-594 https://doi.org/10.1111/evj.12481 